\title{
Morbidity, mortality, and categorization of the risk of perioperative complications in lung cancer patients*
}

\author{
Mortalidade, morbidade e categorização de risco para complicações \\ perioperatórias em pacientes com câncer de pulmão
}

\author{
Fabiana Stanzani, Denise de Moraes Paisani, Anderson de Oliveira, \\ Rodrigo Caetano de Souza, João Aléssio Juliano Perfeito, \\ Sonia Maria Faresin
}

\begin{abstract}
Objective: To determine morbidity and mortality rates by risk category in accordance with the American College of Chest Physicians guidelines, to determine what role pulmonary function tests play in this categorization process, and to identify risk factors for perioperative complications (PCs). Methods: This was a historical cohort study based on preoperative and postoperative data collected for cases of lung cancer diagnosed or suspected between 2001 and 2010. Results: Of the 239 patients evaluated, only 13 (5.4\%) were classified as being at high risk of PCs. Predicted postoperative FEV (FEV, ppo) was sufficient to define the risk level in 156 patients (65.3\%); however, cardiopulmonary exercise testing (CPET) was necessary for identifying those at high risk. Lung resection was performed in 145 patients. Overall morbidity and mortality rates were similar to those reported in other studies. However, morbidity and mortality rates for patients at an acceptable risk of PCs were 31.6\% and 4.3\%, respectively, whereas those for patients at high risk were 83.3\% and 33.3\%. Advanced age, COPD, lobe resection, and lower FEV ppo were correlated with PCs. Conclusions: Although spirometry was sufficient for risk assessment in the majority of the population studied, CPET played a key role in the identification of high-risk patients, among whom the mortality rate was seven times higher than was that observed for those at an acceptable risk of PCs. The risk factors related to PCs coincided with those reported in previous studies.
\end{abstract}

Keywords: Algorithms; lung neoplasms; Postoperative complications.

\section{Resumo}

Objetivo: Determinar as taxas de morbidade e mortalidade por categoria de risco conforme as diretrizes do American College of Chest Physicians, verificar como exames funcionais participaram dessa categorização e identificar fatores de risco para complicações perioperatórias (CPOs). Métodos: Estudo de coorte histórica a partir de avaliações pré e pós-operatórias de casos diagnosticados ou suspeitos de câncer de pulmão avaliados entre 2001 e 2010. Resultados: Dos 239 pacientes avaliados, apenas 13 (5,4\%) foram considerados como de alto risco para CPOs. 0 cálculo do $\mathrm{VEF}_{1}$ previsto para o pós-operatório $\left(\mathrm{VEF}_{1} \mathrm{ppo}\right)$ foi suficiente para a estratificação do risco em 156 pacientes (65,3\%); entretanto, o teste de exercício cardiopulmonar (TECP) foi necessário para a identificação de alto risco. Foram operados 145 pacientes, e as taxas globais de morbidade e mortalidade encontradas foram semelhantes às de outros estudos. Entretanto, as taxas de morbidade e mortalidade para aqueles com risco aceitável foram de 31,6\% e 4,3\%, respectivamente, enquanto as taxas para aqueles com alto risco foram de $83,3 \%$ e $33,3 \%$. ldade mais avançada, presença da DPOC, ressecção de um ou mais lobos e VEF $F_{1}$ p po mais baixo estiveram relacionados à ocorrência de CPOs. Conclusões: Embora a espirometria tenha sido suficiente para a determinação de risco na maioria da população estudada, o TECP teve papel fundamental na identificação de pacientes com risco alto, que apresentaram uma taxa de mortalidade sete vezes maior que os de risco aceitável. Os fatores de risco relacionados a CPOs coincidiram aos relatados em outros estudos.

Descritores: Algoritmos; Neoplasias pulmonares; Complicações pós-operatórias.

*Study carried out in the Pulmonology Section, Department of Medicine, Federal University of São Paulo, São Paulo, Brazil. Correspondence to: Fabiana Stanzani. Rua Dr. Afonso Baccari, 71, apto 103, Vila Clementino, CEP 04026-030, São Paulo, SP, Brasil. Tel. 5511 3253-4331. E-mail: fabiana.stanzani@uol.com.br Financial support: None.

Submitted: 25 July 2012. Accepted, after review: 28 October 2013. 


\section{Introduction}

Functional evaluation of candidates for lung resection for the treatment of lung cancer can be guided by various algorithms, of which the most known are those proposed by the consensus guidelines of the American College of Chest Physicians (ACCP) ${ }^{(1)}$ and the European Respiratory Society/European Society of Thoracic Surgeons. ${ }^{(2)}$ Although the use of these tools would potentially reduce morbidity and mortality rates, their application is compromised, because tests that are not readily available for most physicians, such as DLCO measurement and, especially, cardiopulmonary exercise testing (CPET), are required..$^{(3-5)}$

The main difference between the two algorithms lies in the referral for those tests, although there have been no studies comparing the superiority of one over the other. However, it has been reported that, when no algorithm was used, evaluation errors were common, with the highest frequency of these errors occurring among less experienced physicians. ${ }^{(5,6)}$

Having been published before the European algorithm, the ACCP algorithm has been used in the preoperative evaluation center of the Federal University of São Paulo in the last 10 years. The objective of this study was to share our experience by providing morbidity and mortality rates by risk category, as well as to report the role played by DLCO measurement and CPET in this categorization process and the risk factors associated with perioperative complications (PCs).

\section{Methods}

This was a historical cohort study of a database of preoperative evaluations of patients diagnosed with or clinically suspected of having lung cancer, performed at the Hospital São Paulo, located in the city of São Paulo, Brazil, between January 1, 2001 and December 31, 2010. The project was approved by the Research Ethics Committee of the Federal University of São Paulo (Protocol no. $1487 / 11)$.

The evaluation algorithm proposed by the ACCP consensus guidelines was applied after patients had achieved their best clinical and functional status. Figure 1 illustrates the algorithm and the surgical risk categorization. All patients underwent spirometry, and referral for DLCO measurement occurred when there was clinical and radiological suspicion of concomitant interstitial disease, when there was a history of neoadjuvant chemotherapy, or when the intensity of dyspnea reported was disproportionate to the measured FEV ${ }_{1}$ as a percentage of the predicted value. Referral for CPET occurred when either predicted postoperative FEV $_{1}\left(\mathrm{FEV}_{1}\right.$ ppo) or predicted postoperative DLCO (DLCOppo) was less than $40 \%$, or when the patient was unable to perform acceptable DLCO measurement maneuvers. Patients who were unable to perform CPET properly were classified as being at high risk.

In the post-operative period, patients received physical therapy and pain management from specialized teams until they were discharged from the hospital.

The outcome measures analyzed, i.e., morbidity and mortality rates, included events occurring by postoperative day 30. Described in a previous study, ${ }^{(7)}$ the definitions of PCs were as follows: respiratory or cardiovascular events causing intraoperative instability; lower respiratory tract infection; atelectasis; acute respiratory failure; acute myocardial infarction; atrial arrhythmia requiring treatment; congestive heart failure; bronchopleural fistula; pleural empyema; air leak lasting 7 days or longer; hemothorax; reoperation; and need for oxygen therapy on postoperative day 30.

In the statistical analysis, morbidity and mortality rates are expressed as simple percentages. In order to determine whether the functional values were associated with PCs, we had to recalculate them, adjusting them to the extent of the resection performed rather than maintaining them in accordance with the planned resection. The resulting values were called true FEV and true DLCOppo. In order to identify which variables were correlated with PCs, we used Pearson's chi-square test and the Student's t-test.

\section{Results}

Of the 262 who were eligible for the study, 239 (91.2\%) underwent all steps of the ACCP algorithm, whereas $23(8.8 \%)$ did not. The clinical and functional characteristics of those 239 patients are shown in Table 1.

In 156 patients (65.3\%), $\mathrm{FEV}_{1}$ was $\geq 80 \%$ or $\mathrm{FEV}_{1}$ ppo was $\geq 40 \%$, and no other tests were needed to complete the evaluation. However, 8 patients $(3.3 \%)$ had a $\mathrm{FEV}_{1}$ ppo $\leq 40 \%$ and were therefore referred for CPET. 


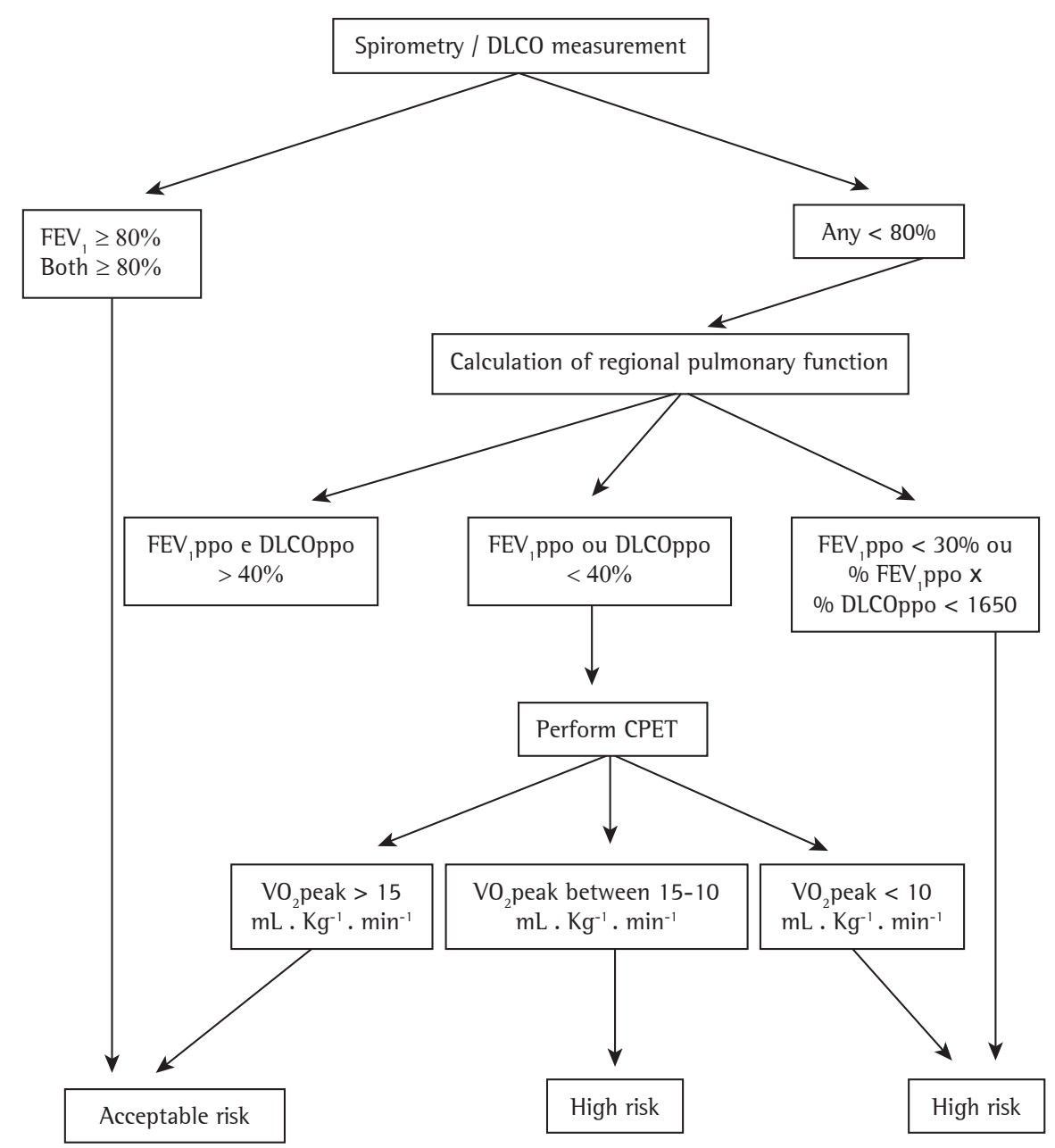

Figure 1 - Algorithm proposed by the American College of Chest Physicians. ppo: predicted postoperative; CPET: cardiopulmonary exercise testing; and $\mathrm{VO}_{2}$ peak: peak oxygen uptake.

Table 1 - Demographic, clinical, and pulmonary function data of the 239 candidates evaluated. ${ }^{a}$

\begin{tabular}{lc}
\hline \multicolumn{1}{c}{ Variable } & Result \\
\hline Age, years & \\
Neoadjuvant chemotherapy & $59.0 \pm 12.0$ \\
COPD & $78(7.1)$ \\
Other comorbidities & $104(43.6)$ \\
Systemic arterial hypertension & $93(89.4)$ \\
Diabetes mellitus & $35(33.6)$ \\
Coronary artery disease $_{\text {Chronic renal disease }}$ & $7(6.7)$ \\
Heart failure $_{\text {FEV }_{1}, \% \text { of predicted }}{ }^{\mathrm{b}}$ & $5(4.8)$ \\
DLCO, \% of predicted $^{\mathrm{b}}$ & $2(1.9)$ \\
\hline
\end{tabular}

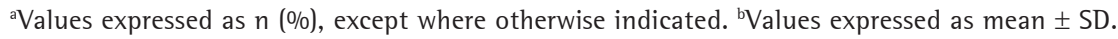

Of the 239 patients, $82(34.3 \%)$ were referred for DLCO measurement. However, 6 of those 82 did not undergo DLCO measurement because they were unable to perform acceptable maneuvers. Of the 76 remaining patients, $60(73.2 \%)$ had FEV $_{1}$ ppo and DLCOppo values $>40 \%$ predicted 
and were classified, at the end of the preoperative evaluation, as being at an acceptable risk of PCs. Of the 14 patients who had a DLCOppo < 40\%, 13 had a FEV ${ }_{1}$ ppo $>40 \%$. A total of 23 patients (9.6\%) were referred for CPET, and 13 (56.5\%) of them were classified as being at high risk for the following reasons: having a peak oxygen uptake $\leq 15 \mathrm{~mL} \bullet \mathrm{kg}^{-1} \bullet \mathrm{min}^{-1}$ (6 patients); performing submaximal exercise or being unable to pedal (4 patients); not having undergone CPET because of an unknown reason (2 patients); and not having undergone CPET because the machine was broken ( 1 patient). Figure 2 illustrates the application of the algorithm, which classified 13 patients (5.4\%) as being at high risk of PCs and $226(94.6 \%)$ as being at an acceptable risk.

One hundred and fifty-one patients (63.2\%) were operated on. Six of them did not undergo resection of lung parenchyma and were therefore disregarded in the remaining analyses. Of the remainder, 139 and 6 were classified as being at an acceptable and high risk, respectively. In $49.6 \%$ of those procedures, the amount of parenchyma resected was smaller than planned; in most cases, because malignant disease was ruled out by intraoperative frozen-section analysis. In 9.3\%, a greater amount of tissue was resected because of the progression of cancer. The following procedures were performed: lobectomy (in 38.6\% of the cases); resection of less than one segment (in 29.0\%); segmentectomy (in 17.9\%); pneumonectomy (in 8.3\%); bilobectomy (in 4.8\%); and bisegmentectomy (in 1.4\%).

Of the 145 patients operated on, 49 had PCs, the morbidity rate being $33.8 \%$ and the overall mortality rate being $5.5 \%$ (8 deaths). There were $101 \mathrm{PCs}$, the most common being prolonged air leak (in 19.8\%), lower airway respiratory infection (in 19.8\%), and acute respiratory failure (in 17.8\%), followed by cardiac arrhythmia (in 7.9\%), need for reoperation (in 5.9\%), home oxygen therapy (in 5.9\%), pleural empyema (in $5.9 \%$ ), atelectasis (in 5.0\%), acute myocardial infarction (in 5.0\%), bronchopleural fistula (in 4.0\%), and intraoperative events (in 3.0\%).

There were no statistically significant differences between operated and non-operated patients in terms of age, prevalence of comorbidities, prevalence of COPD, or $\mathrm{FEV}_{1}$ as a percentage of the predicted value. The most common reasons preventing surgical treatment were progression of cancer, treatment discontinuation or dropout, and a diagnosis of benign disease by a method other than the initially planned surgery.

A diagnosis of malignancy was confirmed in 105 operated patients $(72.4 \%)$, adenocarcinoma being the most common histological type (in $40.0 \%) . \ln 27.6 \%$ of the patients, the histological diagnoses were benign, the majority (59.5\%) corresponding to nonspecific benign lesions and tuberculomas.

Morbidity and mortality rates for patients classified preoperatively as being at an acceptable risk of PCs were, respectively, 31.6\% and 4.3\% (6 deaths), whereas those for patients at high risk were $83.3 \%$ and $33.3 \%$ (2 deaths). In the reclassification of patients by extent of the procedure, 4 of the 139 patients classified as being at an acceptable risk would be referred for CPET so that the evaluation could be completed. Of the 6 patients classified as being at high risk, 4 remained so and 2 were reclassified as being at an acceptable risk. After recalculation, morbidity and mortality rates were, respectively, $31.4 \%$ and 3.6\% for those at an acceptable risk and $100 \%$ and $50.0 \%$ for those at high risk. Table 2 shows the morbidity and mortality rates of patients classified as being at an acceptable risk, by tests performed.

In a comparison of patients who had PCs with those who did not, statistically significant differences were found in the following variables: age; lobe resection; true FEV ${ }_{1}$ ppo as a percentage of the predicted value; and COPD (Table 3).

\section{Discussion}

The use of the ACCP algorithm showed that, among patients classified as being at high risk of PCs, the mortality rate was seven to thirteen times higher than was that observed for those classified as being at an acceptable risk. This difference occurred in the context of overall morbidity and mortality rates being consistent with those reported by other health care facilities. ${ }^{(8-10)}$ This finding revealed that the algorithm provided a good prediction of patient risk, identifying those who require more attention and investment both before and after the procedure.

Whereas only calculation of $\mathrm{FEV}_{1}$ ppo was needed in the evaluation of the majority of the study population, who had a favorable postoperative course, a DLCOppo value < $40 \%$ determined the need for CPET five times more often than did a $\mathrm{FEV}_{1}$ ppo value $<40 \%$. 


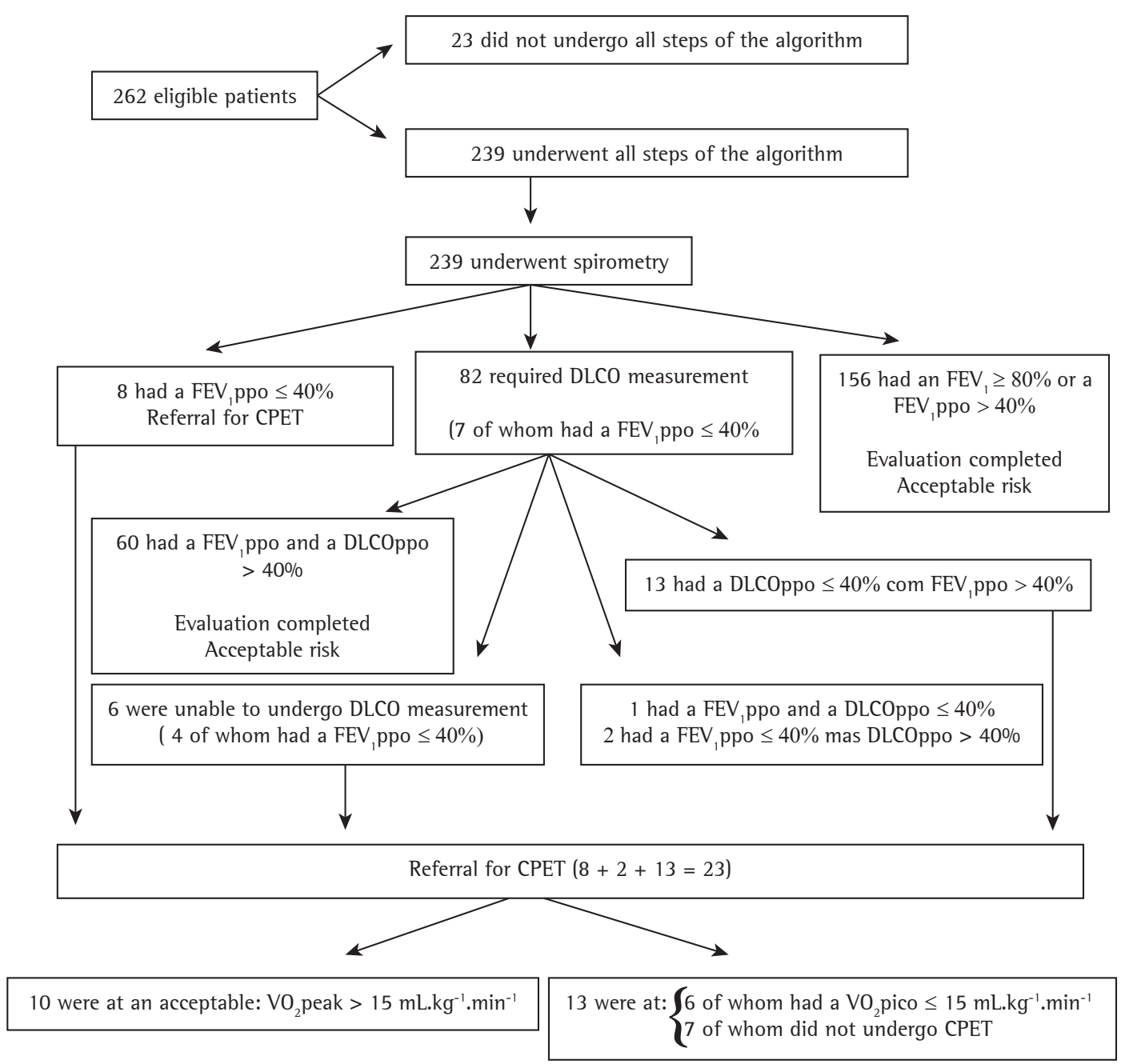

Figure 2 - Preoperative evaluation of 239 lung resection candidates as per the American College of Chest Physicians algorithm guidelines. ppo: predicted postoperative; CPET: cardiopulmonary exercise testing; and $\mathrm{VO}_{2}$ peak: peak oxygen uptake.

Table 2 - Morbidity and mortality rates of the 137 patients reclassified as being at an acceptable risk of perioperative complications after the surgical procedure, by tests performed.

\begin{tabular}{lccc}
\hline \multicolumn{1}{c}{ Tests performed } & Patients & Morbidity rate & Mortality rate \\
\cline { 2 - 4 } & $\mathrm{n}(\%)$ & $(\%)$ & $(\%)$ \\
\hline Spirometry & $101(73.7)$ & 26.7 & 4.0 \\
Spirometry + DLC0 measurement & $30(21.9)$ & 33.3 & 0.0 \\
Spirometry + DLC0 measurement + CPET & $6(4.4)$ & 83.3 & 16.7 \\
\hline
\end{tabular}

CPET: cardiopulmonary exercise testing.

However, considering the subgroup of patients who underwent this test, the risk level did not change in $75 \%$ of the cases. This result was unexpected, given that DLCO has gained much prominence in postoperative evaluation in recent years, with several studies demonstrating that DLCO is more accurate for predicting risk of PCs than is $\mathrm{FEV}_{1} \cdot{ }^{(11-13)} \mathrm{A}$ likely explanation for this is loss of discriminatory power of DLCO when DLCO is included in an algorithm that classifies patients into only two categories. However, it should also be considered that, if our sample was bigger or if all patients had undergone DLCO measurement, the results could perhaps 
Table 3 - Comparison between the groups of patients with and without perioperative complications in terms of age, presence of COPD, presence of other comorbidities, size of resection, and pulmonary function parameters.

\begin{tabular}{|c|c|c|c|}
\hline \multirow[t]{2}{*}{ Variable } & \multicolumn{2}{|c|}{ Group } & \multirow[t]{2}{*}{$\mathrm{p}^{*}$} \\
\hline & With PCs & Without PCs & \\
\hline Age, years & $57.6 \pm 11.5$ & $61.8 \pm 12.0$ & 0.044 \\
\hline COPD & 25.0 & 54.2 & 0.001 \\
\hline Other comorbidities & 52.1 & 36.7 & 0.080 \\
\hline Lobe resection & 44.8 & 65.3 & 0.003 \\
\hline True FEV & $81.4 \pm 22.3$ & $67.9 \pm 22.5$ & 0.001 \\
\hline
\end{tabular}

PCs: perioperative complications; and ppo: \% of predicted, postoperative. *Pearson's chi-square test and the Student's t-test.

be different, allowing even the creation of other categories, such as the moderate risk category.

Certainly, CPET is the method of choice for surgical risk stratification even outside the field of thoracic surgery; however, it is not widely available. ${ }^{(14,15)}$ Our results showed that, when CPET is used after a series of tests that identified a patient as having limited reserve, which corresponded to only $9.6 \%$ of our population, the risk would be high in $56.6 \%$ of the cases. However, it is necessary to consider that the observed rates of PCs and mortality were very high. In our view, the algorithm used was designed in such a way that the high-risk category corresponded to "very high risk", and, therefore, the algorithm should be improved by the inclusion of intermediate-risk categories.

According to the European algorithm, CPET should be performed when the predicted FEV or DLCO value is below $80 \%$, i.e., in the initial phase of the evaluation. This recommendation was based primarily on the studies by Bolliger et al., ${ }^{(3,4)}$ who had this test available at their facility and developed an algorithm on the basis of it. In contrast, the cost-effectiveness of this approach as compared with that of simpler evaluation strategies, especially in low-risk patients, is unknown. If we had applied the European algorithm to our sample, $81.7 \%$ of the population should have undergone CPET. A recent study conducted in Spain showed that, when six hospitals used that algorithm, of the 92 patients (53.2\%) of the study sample who had been referred for CPET, only 68 underwent the test. In most cases, the test was not performed because of a lack of technical infrastructure. ${ }^{(16)}$

During the review process of our manuscript, the third revision of the ACCP guidelines for the evaluation of lung resection candidates was published. ${ }^{(17)}$ A new algorithm, extrapolated from a number of studies, was proposed, but, unfortunately, it was not validated in a large, multicenter, prospective study. In comparison with the 2007 guidelines, these new guidelines agree with the European algorithm that all resection candidates should undergo DLCO measurement, as well as including the use of submaximal exercise tests before CPET, the development of new parameters for categorizing low risk, and the creation of a moderate-risk category. Therefore, when FEV ${ }_{1}$ ppo and DLCOppo were above 60\%, patients would be classified as being at low risk. If either of these parameters was between 30\% and $60 \%$, patients would be referred for the shuttle test or the stair-climbing test. Depending on the results obtained, patients would undergo CPET, the results of which would determine whether the patient would be classified into the low-risk, moderate-risk, or high-risk category.

In an attempt to simplify the dynamic evaluation of cardiopulmonary reserve, much research has been conducted on submaximal exercise tests, such as the stair-climbing test, the six-minute walk test (6MWT), and the shuttle test. ${ }^{(18-20)}$ Despite the satisfactory findings reported, some negative points have been observed. The lack of standardization of the stair-climbing test, the low level of evidence of the 6MWT, the variability of effort exerted during the tests, and, first and foremost, the fact that none of these tests measure more complex metabolic and cardiopulmonary parameters reserved for them the role of ascertaining if the patient really was at low risk of PCs. The European consensus guidelines and the ACCP consensus guidelines agree that patients who perform poorly on these tests should undergo CPET. It is likely that further studies will discuss whether or not the strategy of using submaximal exercise tests within the new 
algorithm will prove sufficiently discriminatory and cost-effective.

Given these findings, we suspect that the major problem may lie in the proposed algorithms rather than in the availability of the tests. In an attempt to verify this suspicion, our suggestion would be to start the investigative process after determining which PCs would be considered significant for this type of procedure, in order to determine the morbidity rate. Goals would then be set on the basis of morbidity and mortality rates considered tolerable for each risk category. Investigations would identify which tests and which results would be needed in order to achieve each goal, determining how much accuracy would be gained by including more sophisticated tests in each category. An algorithm designed in such a way would perhaps give greater assurance to the surgeon and the patient, as well as resulting in better use of more complex tests and of multidisciplinary teams as risk increased. This reasoning results from the difficulty we face in comparing the rates of PCs and death found in the present study with those reported in other studies, as well as from the hypothesis formulated on the basis of our findings, i.e., CPET plays a more decisive role in differentiating between the high-risk and very high-risk categories and in clinical treatment.

Although CPET is available at our facility, we will continue to recommend it only for patients with limited reserve, because, since ours is a public health care facility, we do not have sufficient resources or logistics capacity to meet the demand generated by the use of the European algorithm. In addition, as seen in Table 2, the morbidity and mortality rates obtained for the acceptablerisk category by using spirometry and DLCO measurement were satisfactory.

The occurrence of PCs is always a cause for concern. For patients, it means longer hospital stays, a greater delay in resuming work and social activities, and higher medical and hospital expenses, as well as adding to the risk of sequelae or death. As in recent studies, the rate of observed cardiac complications was lower than that of pulmonary complications..$^{(9,21)}$ One possible explanation could be care in recognizing and treating cardiac comorbidities prior to evaluation for resection, a recommendation made by both the ACCP algorithm and the European algorithm. Studies have shown that the implementation of a preoperative cardiac evaluation algorithm contributed to proper use of tests and therapeutic strategies, reducing cardiac morbidity rates. ${ }^{(22,23)}$ Another contributing factor would be advances in the diagnosis and treatment of dyslipidemia, systemic arterial hypertension, diabetes mellitus, and coronary artery disease, reducing the systemic inflammatory state.

It remains controversial whether advanced age alone is a risk factor for $\mathrm{PCs}^{(24,25)}$ or whether the severity and number of comorbidities that affect older patients are responsible for these complications. ${ }^{(9,26-28)}$ The prevalence rate of comorbidities found in our study was similar to or lower than those reported in other studies, ${ }^{(8,9,29)}$ as well as being similar between the groups with and without PCs. The opposite was true for the presence of COPD and the extent of resection, which are known to be the two most important risk factors related to PCs. ${ }^{(4,9,24)}$

The present study had some limitations. The first of these limitations was the study's retrospective design. Therefore, we prioritized addressing complications that have the greatest impact, have established definitions, and had been used in other studies conducted at out facility, such as pulmonary infection, acute respiratory failure, and bronchopleural fistula. The second limitation was the modest number of patients studied, which precluded more complex statistical analysis. However, this is the first report of the use of the ACCP algorithm in Brazil. The third limitation was the possibility that critically ill patients were not referred to our outpatient clinic because they had previously been considered as being at very high risk. Therefore, the findings of the present study should not be generalized.

In conclusion, the use of the ACCP algorithm allowed the identification of a group of patients whose morbidity and mortality rates were considerably higher, requiring more attention throughout the perioperative period. The majority of our population was evaluated on the basis of spirometry alone and had acceptable morbidity and mortality rates. However, CPET played an important role in the identification of high-risk patients. In agreement with published studies, advanced age, COPD, lobe resection, and poorer pulmonary function were correlated with PCs.

\section{Acknowledgments}

We would like to thank the patients, who place their hopes in our hands, and we humbly 
express our sincere and heartfelt gratitude to dear Professor Vicente Forte (in memoriam), our master and guide. We thank him for his firm presence in this project when he was among us, and, afterwards, for being a source of insight and inspiration.

\section{References}

1. Colice GL, Shafazand S, Griffin JP, Keenan R, Bolliger CT; American College of Chest Physicians. Physiologic evaluation of the patient with lung cancer being considered for resectional surgery: ACCP evidenced-based clinical practice guidelines (2nd edition). Chest. 2007;132(3 Suppl):161S-77S.

2. Brunelli A, Charloux A, Bolliger CT, Rocco G, Sculier JP, Varela G, et al. ERS/ESTS clinical guidelines on fitness for radical therapy in lung cancer patients (surgery and chemo-radiotherapy). Eur Respir J. 2009;34(1):17-41. Erratum in: Eur Respir J. 2009;34(3):782. http://dx.doi. org/10.1183/09031936.00184308 PMid:19567600

3. Bolliger CT, Jordan P, Solèr M, Stulz P, Grädel E, Skarvan $\mathrm{K}$, et al. Exercise capacity as a predictor of postoperative complications in lung resection candidates. Am J Respir Crit Care Med. 1995;151(5):1472-80. http://dx.doi. org/10.1164/ajrccm.151.5.7735602 PMid:7735602

4. Wyser C, Stulz P, Solèr M, Tamm M, Müller-Brand J, Habicht J, et al. Prospective evaluation of an algorithm for the functional assessment of lung resection candidates. Am J Respir Crit Care Med. 1999;159(5 Pt 1):1450-6. http:// dx.doi.org/10.1164/ajrccm.159.5.9809107 PMid:10228110

5. Charloux A, Brunelli A, Bolliger CT, Rocco G, Sculier JP, Varela G, et al. Lung function evaluation before surgery in lung cancer patients: how are recent advances put into practice? A survey among members of the European Society of Thoracic Surgeons (ESTS) and of the Thoracic Oncology Section of the European Respiratory Society (ERS). Interact Cardiovasc Thorac Surg. 2009;9(6):925-31. http:// dx.doi.org/10.1510/icvts.2009.211219 PMid:19752152

6. Ferguson MK, Stromberg JD, Celauro AD. Estimating lung resection risk: a pilot study of trainee and practicing surgeons. Ann Thorac Surg. 2010;89(4):1037-42; discussion 1042-3. http://dx.doi.org/10.1016/j.athoracsur.2009.12.068 PMid:20338304

7. Stanzani F, Oliveira MA, Forte V, Faresin SM. Torrington and Henderson and Epstein risk assessment scales: applicability and effectiveness in lung resection. J Bras Pneumol. 2005;31(4):292-9. http://dx.doi.org/10.1590/ S1806-37132005000400005

8. Harpole DH Jr, DeCamp MM Jr, Daley J, Hur K, Oprian CA, Henderson WG, et al. Prognostic models of thirty-day mortality and morbidity after major pulmonary resection. J Thorac Cardiovasc Surg. 1999;117(5):969-79. http:// dx.doi.org/10.1016/S0022-5223(99)70378-8

9. Boffa DJ, Allen MS, Grab JD, Gaissert HA, Harpole $\mathrm{DH}$, Wright CD. Data from The Society of Thoracic Surgeons General Thoracic Surgery database: the surgical management of primary lung tumors. J Thorac Cardiovasc Surg. 2008;135(2):247-54. http://dx.doi.org/10.1016/j. jtcvs.2007.07.060 PMid:18242243

10. Sánchez PG, Vendrame GS, Madke GR, Pilla ES, Camargo Jde J, Andrade CF, et al. Lobectomy for treating bronchial carcinoma: analysis of comorbidities and their impact on postoperative morbidity and mortality. J Bras Pneumol.
2006;32(6):495-504. http://dx.doi.org/10.1590/S180637132006000600005 PMid:17435899

11. Ferguson MK, Little L, Rizzo L, Popovich KJ, Glonek GF, Leff A, et al. Diffusing capacity predicts morbidity and mortality after pulmonary resection. J Thorac Cardiovasc Surg. 1988;96(6):894-900. PMid:3193801

12. Ferguson MK, Gaissert HA, Grab JD, Sheng S. Pulmonary complications after lung resection in the absence of chronic obstructive pulmonary disease: the predictive role of diffusing capacity. J Thorac Cardiovasc Surg. 2009;138(6):1297-302. http://dx.doi.org/10.1016/j. jtcvs.2009.05.045 PMid:19783010

13. Brunelli A, Refai MA, Salati M, Sabbatini A, Morgan-Hughes NJ, Rocco G. Carbon monoxide lung diffusion capacity improves risk stratification in patients without airflow limitation: evidence for systematic measurement before lung resection. Eur J Cardiothorac Surg. 2006;29(4):56770. http://dx.doi.org/10.1016/j.ejcts.2006.01.014 PMid:16481190

14. Smith TB, Stonell C, Purkayastha S, Paraskevas P. Cardiopulmonary exercise testing as a risk assessment method in non cardio-pulmonary surgery: a systematic review. Anaesthesia. 2009;64(8):883-93. http://dx.doi. org/10.1111/j.1365-2044.2009.05983.x PMid:19604193

15. Older P, Smith R, Hall A, French C. Preoperative cardiopulmonary risk assessment by cardiopulmonary exercise testing. Crit Care Resusc. 2000;2(3):198-208. PMid:16599898

16. Novoa NM, Ramos J, Jiménez MF, González-Ruiz JM, Varela G. The initial phase for validating the European algorithm for functional assessment prior to lung resection: quantifying compliance with the recommendations in actual clinical practice. Arch Bronconeumol. 2012;48(7):22933. http://dx.doi.org/10.1016/j.arbr.2012.05.001 PMid:22513266

17. Brunelli A, Kim AW, Berger Kl, Addrizzo-Harris DJ. Physiologic evaluation of the patient with lung cancer being considered for resectional surgery: Diagnosis and management of lung cancer, 3rd ed: American College of Chest Physicians evidence-based clinical practice guidelines. Chest. 2013;143(5 Suppl):e166S-90S.

18. Brunelli A, Refai M, Xiumé F, Salati M, Sciarra V, Socci L, et al. Performance at symptom-limited stair-climbing test is associated with increased cardiopulmonary complications, mortality, and costs after major lung resection. Ann Thorac Surg. 2008;86(1):240-7; discussion 247-8. http://dx.doi. org/10.1016/j.athoracsur.2008.03.025 PMid:18573431

19. Nomori H, Watanabe K, Ohtsuka T, Naruke T, Suemasu $\mathrm{K}$. Six-minute walking and pulmonary function test outcomes during the early period after lung cancer surgery with special reference to patients with chronic obstructive pulmonary disease. Jpn J Thorac Cardiovasc Surg. 2004;52(3):113-9. http://dx.doi.org/10.1007/ s11748-004-0126-8 PMid:15077844

20. Win T, Jackson A, Groves AM, Sharples LD, Charman SC, Laroche CM. Comparison of shuttle walk with measured peak oxygen consumption in patients with operable lung cancer. Thorax. 2006;61(1):57-60. http:// dx.doi.org/10.1136/thx.2005.043547 PMid:16244091 PMCid:PMC2080711

21. Ferguson MK, Vigneswaran WT. Changes in patient presentation and outcomes for major lung resection over three decades. Eur J Cardiothorac Surg. 2008;33(3):497501. http://dx.doi.org/10.1016/j.ejcts.2007.12.023 PMid:18221882 
22. Almanaseer Y, Mukherjee D, Kline-Rogers EM, Kesterson SK, Sonnad SS, Rogers B, et al. Implementation of the ACC/AHA guidelines for preoperative cardiac risk assessment in a general medicine preoperative clinic: improving efficiency and preserving outcomes. Cardiology. 2005;103(1):24-9. http://dx.doi.org/10.1159/000081848 PMid:15528897

23. Cagirici U, Nalbantgil S, Cakan A, Turhan K. A new algorithm for preoperative cardiac assessment in patients undergoing pulmonary resection. Tex Heart lnst J. 2005;32(2):159-62. PMid:16107106 PMCid:PMC1163462

24. Smetana GW, Lawrence VA, Cornell JE; American College of Physicians. Preoperative pulmonary risk stratification for noncardiothoracic surgery: systematic review for the American College of Physicians. Ann Intern Med. 2006;144(8):581-95. http://dx.doi. org/10.7326/0003-4819-144-8-200604180-00009

25. Dominguez-Ventura A, Cassivi SD, Allen MS, Wigle DA, Nichols FC, Pairolero PC, et al. Lung cancer in octogenarians: factors affecting long-term survival following resection. Eur J Cardiothorac Surg. 2007;32(2):370-4. http://dx.doi.org/10.1016/j. ejcts.2007.04.002 PMid:17555978
26. Algar FJ, Alvarez A, Salvatierra A, Baamonde C, Aranda JL, López-Pujol FJ. Predicting pulmonary complications after pneumonectomy for lung cancer. Eur J Cardiothorac Surg. 2003;23(2):201-8. http://dx.doi.org/10.1016/ S1010-7940(02)00719-4

27. Birim 0, Zuydendorp HM, Maat AP, Kappetein AP, Eijkemans MJ, Bogers AJ. Lung resection for non-smallcell lung cancer in patients older than 70: mortality, morbidity, and late survival compared with the general population. Ann Thorac Surg. 2003;76(6):1796-801. http://dx.doi.org/10.1016/S0003-4975(03)01064-6

28. Brunelli A, Monteverde M, Al Refai M, Fianchini A. Stair climbing test as a predictor of cardiopulmonary complications after pulmonary lobectomy in the elderly. Ann Thorac Surg. 2004;77(1):266-70. http://dx.doi. org/10.1016/S0003-4975(03)01327-4

29. Ferguson MK, Vigneswaran WT. Changes in patient presentation and outcomes for major lung resection over three decades. Eur J Cardiothorac Surg. 2008;33(3):497501. http://dx.doi.org/10.1016/j.ejcts.2007.12.023 PMid:18221882

\section{About the authors}

\section{Fabiana Stanzani}

Physician. Pulmonology Section, Department of Medicine, Federal University of São Paulo, São Paulo, Brazil.

\section{Denise de Moraes Paisani}

Physiotherapist. São Paulo, Brazil.

\section{Anderson de Oliveira}

Thoracic Surgeon. Arnaldo Vieira de Carvalho Cancer Institute, São Paulo, Brazil.

\section{Rodrigo Caetano de Souza}

Thoracic Surgeon. Thoracic Surgeon Section, Department of Medicine, Federal University of São Paulo, São Paulo, Brazil.

\section{João Aléssio Juliano Perfeito}

Thoracic Surgeon. Thoracic Surgeon Section, Department of Medicine, Federal University of São Paulo, São Paulo, Brazil.

\section{Sonia Maria Faresin}

Affiliate Professor. Pulmonology Section, Department of Medicine, Federal University of São Paulo, São Paulo, Brazil. 